MISES: Revista Interdisciplinar de Filosofia, Direito e Economia

ISSN 2318-0811

Volume III, Número 1 (Edição 5) Janeiro-Junho 2015: 215-228

\title{
Merquior, um Liberista? Uma Comparação entre o Pensamento Liberal de José Guilherme Merquior e o de Friedrich von Hayek
}

\author{
Kaio Felipe*
}

\begin{abstract}
Resumo: Neste ensaio, busco esclarecer a posição ideológica de José Guilherme Merquior: seria ele um liberista (isto é, um liberal com ênfase na liberdade econômica) ou um social-liberal (ou seja, mais preocupado com a participação cívica e com o auto-aperfeiçoamento)? Além disso, pretendo analisar como Merquior se coloca em relação às formulações teóricas e políticas de Friedrich August von Hayek, na medida em que este é um dos autores liberais mais citados e discutidos em suas obras da década de 1980.
\end{abstract}

Palavras-Chave: Liberdade, Liberalismo, Liberismo, Democracia, Filosofia Política.

\section{Merquior, a Liberist? A Comparison of the Liberal Thought of José Guilherme Merquior and Friedrich von Hayek}

\begin{abstract}
In this essay I seek to clarify the ideological viewpoint of José Guilherme Merquior: was he a liberist (i.e., a liberal which emphasizes the economic freedom) or a social-liberal (i.e., more concerned with civic participation and self-improvement)? In addition, I intend to analyze how Merquior stands in relation to theoretical and political formulations of Friedrich August von Hayek, considering that this is one of the liberal authors most cited and discussed in his works of the 1980s.

Keywords: Freedom, Liberalism, Liberism, Democracy, Political Philosophy.
\end{abstract}

Classificação JEL: Y80

\footnotetext{
" Kaio Felipe é doutorando em Sociologia no Instituto de Estudos Sociais e Políticos da Universidade do Estado do Rio de Janeiro (IESP-UERJ) e em História Social da Cultura na Pontifícia Universidade Católica do Rio de Janeiro (PUC-Rio). Cursou a graduação em Ciência Política na Universidade de Brasília (UnB) e o mestrado em Ciência Política no IESP-UERJ. Foi bolsista do Programa de Educação Tutorial em Ciência Política (PET-POL) e participou do programa de estágio-docência ministrando as disciplinas introdutórias de Sociologia para os cursos de graduação da UERJ. Estuda temas relacionados às áreas de Política e Literatura, Sociologia da Literatura e Teoria Política, tendo pesquisado a representação do conceito de Bildung (formação) nas obras do escritor Thomas Mann e, atualmente, se dedicado ao estudo do pensamento de José Guilherme Merquior. É autor de diversos artigos publicados em diferentes periódicos acadêmicos.

E-mail: kaiofelipe@gmail.com
} 


\section{I - INTRODUÇÃO}

Na década de 1920, diante das tensões nacionalistas e das dificuldades econômicas após a I Guerra Mundial, os adeptos do liberalismo clássico encontravam cada vez mais dificuldade de "manter a crença de que o advento do capitalismo industrial havia trazido prosperidade e liberdade para todos"1.

Uma das propostas para resolver essa crise ideológica foi oferecida pelo filósofo italiano Benedetto Croce (1866-1952), que cunhou o termo liberismo, o qual denotava liberdade econômica, para diferenciá-lo do liberalismo enquanto preceito ético-político. Enquanto o primeiro conceito teria como corolário a defesa do capitalismo laissez-faire, o segundo colocaria ênfase maior nas instituições da democracia liberal. Croce alegou que resumir o pensamento liberal à sua faceta economicista seria degradá-lo a um baixo hedonismo utilitário².

Pouco após a II Guerra, este filósofo participou de um frutífero debate com o economista Luigi Einaudi (1874-1961), presidente da Itália entre 1948 e 55, o qual acreditava que a liberdade política era indissociável da liberdade econômica ${ }^{3}$. Croce, por sua vez, insistia na necessidade de separar o liberalismo da ética utilitarista e individualista, acreditando que esta era uma etapa superada, sendo necessário agora combinar o liberalismo político com o dirigismo econômico, síntese esta que geraria o "Estado de bem-estar social" (Welfare State).

\footnotetext{
${ }^{1}$ HEYWOOD, Andrew. Ideologias políticas, [v. 1]: do liberalismo ao fascismo. Trad. Janaína Marcoantonio, Mariane Janikian. São Paulo: Ática, 2010, p. 64.

${ }^{2}$ MERQUIOR, José Guilherme. O Liberalismo: Antigo e Moderno. Trad. Henrique de Araújo Mesquita. Rio de Janeiro: É Realizações, 2014, p. 174.

3 Vide: MERQUIOR, José Guilherme. Algumas Reflexões sobre os Liberalismos Contemporâneos. Rio de Janeiro: Instituto Liberal, 1991, p. 7-11; e ZANFARINO, Antonio. Liberalismo e Liberismo. Il Confronto Croce-Einaudi. In: Studi e Note di Economia, No. 2, 1996, p. 7-19.
}

Se na época Benedetto Croce venceu o debate, quarenta anos depois Einaudi teria uma vitória póstuma: o Ocidente viveu um verdadeiro "renascimento liberal" nas décadas de 80 e 90. Os êxitos políticos de lideranças conservadoras (mas identificadas com preceitos liberalizantes) como Margaret Thatcher (1925-2013) e Ronald Reagan (1911-2004) somaram-se à crise do Welfare State nos países ocidentais e, principalmente, ao colapso do modelo soviético de socialismo, cujo marco simbólico foi a queda do Muro de Berlim, em 1989.

Foi em meio a tal contexto que o economista Roberto Campos (1917-2001) escreveu seu prefácio para o ensaio O Liberalismo: Antigo e Moderno (1991), a última obra (e, de certa maneira, o testamento intelectual ${ }^{4}$ ) do sociólogo e diplomata José Guilherme Merquior (1941-1991). Neste prefácio Campos qualificou Merquior como um liberista:

Em nossas últimas conversas senti que José Guilherme se tornava cada vez mais "liberista". Neste credo, comungávamos. O "liberista" é aquele que acredita que, se não houver liberdade econômica, as outras liberdades - a civil e a política - desaparecem. Na América Latina, a concentração de poder econômico é um exercício liberticida. Nosso diagnóstico sobre a moléstia brasileira era convergente. Ao Brasil de hoje não falta liberdade. Falta liberismo ${ }^{5}$.

Roberto Campos considerava que Merquior era, assim como ele, um liberal clássico que defendia a incompatibilidade entre liberdade política e intervencionismo econômico, e, portanto, advogava um modelo de Estado mínimo. A propósito, não apenas Campos, mas também autores à esquerda de Merquior, como o sociólogo Gilberto Vasconcellos ${ }^{6}$ ten-

\footnotetext{
${ }^{4}$ Vide: ROCHA, João Cezar de Castro. A visão do mundo de José Guilherme Merquior: esta reedição. In: MERQUIOR. O Liberalismo: Antigo e Moderno, p. 324.

5 CAMPOS, Roberto. Merquior, o Liberista. In: MERQUIOR. O Liberalismo: Antigo e Moderno, p. 29.

6 Vide: VASCONCELLOS, Gilberto. A razão da acústica. Folha de São Paulo, 15 de Julho de 2001.
} 
dem a alinhá-lo com o neoliberalismo (tomado aqui como sinônimo de liberismo) preconizado por autores como Milton Friedman (19122006) e Friedrich August von Hayek (18991992).

Considerando que Hayek é justamente um dos teóricos liberais mais discutidos por Merquior em seus ensaios da década de 1980, cabe investigar se essa qualificação realmente procede. O propósito deste ensaio é analisar e interpretar o tipo de liberalismo defendido por José Guilherme Merquior. Será ele realmente um liberista, um neoliberal? Ou estaria, na verdade, alinhado a um liberalismo mais sociopolítico do que econômico, tal como Croce?

\section{II - "An UnREPENTANT OlD Whig": O Liberismo de HayeK}

Antes de tratar da visão de mundo de Merquior, cabe delinear algumas das idéias centrais de F. A. Hayek, mais especificamente as apresentadas em suas obras Os Fundamentos da Liberdade (1960) e Direito, Legislação e Liberdade (1973-1979), na medida em que é sobre ambas que Merquior mais se posiciona.

Em Os Fundamentos da Liberdade, Hayek adere a um conceito de liberdade como ausência de coerção: a propriedade privada e o direito individual de escolha devem ser respeitados, não podendo ficar sob controle arbitrário de uma força externa (geralmente o Estado). Traduzindo tal posição na dicotomia de Isaiah Berlin (1909-1997)7, pode-se dizer que Hayek é mais favorável à liberdade negativa (entendida como não-interferência sobre a forma de os indivíduos usarem as circuns-

Disponível em: <http://www1.folha.uol.com.br/fsp/ mais/fs1507200111.htm>.

7 Vide: BERLIN, Isaiah. Dois conceitos de liberdade. In: Estudos sobre a humanidade: uma antologia de ensaios. Trad. Rosaura Eichenberg. São Paulo: Companhia das Letras, 2002, p. 226-272. tâncias nas quais se encontram ${ }^{8}$ ) do que a $l i$ berdade positiva (isto é, a autonomia, o poder de satisfazer nossos desejos).

Hayek não faz sua apologia da liberdade a partir de um otimismo antropológico, isto é, de uma confiança à moda iluminista no potencial da razão humana; pelo contrário, tece duras críticas à mentalidade especulativa, "construtivista" e planejadora da tradição racionalista, a qual inclui filósofos franceses como Jean-Jacques Rousseau (1712-1778) e Condorcet (1743-1794), mas também possui expoentes britânicos como Jeremy Bentham (1749-1832). Tal linha de pensamento, segundo Hayek, visava à "edificação de uma utopia que se tentou pôr em prática em numerosas ocasiões, sem jamais se conseguir êxito" ${ }^{\prime \prime}$. De fato, é se ancorando em certo ceticismo epistemológico, inspirado em David Hume (1711-1776), que o austríaco justifica a necessidade de limitar o escopo do planejamento governamental sobre a ação humana:

A liberdade é essencial para que o imprevisível exista; nós a desejamos porque aprendemos a esperar dela a oportunidade de realizar a maioria dos nossos objetivos. (...) Por mais humilhante que seja para o orgulho humano, devemos reconhecer que o progresso e até a preservação da civilização dependem de um máximo de oportunidades para que as coisas possam acontecer ${ }^{10}$.

Ainda no segundo capítulo de Os Fundamentos da Liberdade, F. A. Hayek faz uma defesa utilitária da liberdade. Primeiro alega que "o importante não é o tipo de liberdade que eu próprio gostaria de exercer e sim o tipo de liberdade de que alguém pode necessitar para beneficiar a sociedade"11. Em seguida afirma que os benefícios da liberdade existem mesmo que

${ }^{8}$ HAYEK, Friedrich August von. Os Fundamentos da Liberdade. Trad. Anna Maria Capovilla e José Ítalo Stelle. Brasília / São Paulo: Editora Universidade de Brasília / Visão, 1983, p. 15.

${ }^{9}$ Idem. Ibidem, p. 55.

${ }^{10}$ Idem. Ibidem, p. 27-28.

${ }^{11}$ Idem. Ibidem, p. 31. 
ela não seja garantida de forma universal: "é ainda melhor para todos que alguns sejam lives do que ninguém, e, também, bem melhor que muitos possam gozar de plena liberdade do que todos terem uma liberdade restrita"12.

Para tratar de sua auto-definição ideológica, Hayek escreveu o epílogo Por que não sou um conservador. Inicialmente reconhece que conservadorismo é uma legítima, provavelmente necessária e certamente difundida atitude de oposição a mudanças drásticas. $\mathrm{O}$ problema é que, por sua própria natureza reativa, a ideologia conservadora não pode oferecer um objetivo alternativo nem se basear em princípios, o que a torna menos consistente que o liberalismo para oferecer oposição ao socialismo; ou seja, em geral os conservadores simplesmente seguem, dependendo das tendências existentes, os liberais ou socialistas.

Quanto à crítica conservadora à democracia, por um lado Hayek admite não considerar a regra da maioria como um fim, mas apenas como um método, como a forma de governo menos perversa dentre as disponíveis; por outro, considera que o conservadorismo exagera ao atribuir os males de nosso tempo à democracia, quando na verdade o problema não é de regime político, mas sim de limitação dos poderes - e "os poderes que a democracia moderna dispõe seriam ainda mais intoleráveis nas mãos de alguma pequena elite"13.

$\mathrm{Na}$ relação triangular dos partidos, o liberal está numa posição intermediária, pois ao mesmo tempo em que não é contrário à evolução e à mudança (como o conservador), está igualmente longe do "racionalismo primitivo do socialista, que pretende reconstruir todas as instituições de acordo com um padrão prescrito por sua razão individual"14.

Segundo Hayek, o liberalismo do século XIX tem pouco a ver com os movimentos políticos que usavam tal nome na época em que escreveu Os Fundamentos da Liberdade (ou seja,

\footnotetext{
${ }^{12}$ Idem. Ibidem, p. 31.

${ }^{13}$ Idem. Ibidem, p. 473.

${ }^{14}$ Idem. Ibidem, p. 476.
}

em meados da década de 1950). O termo libertário passou a ser usado nos Estados Unidos como sinônimo de liberal no sentido clássico, mas Hayek alega que tal rótulo possui um sabor excessivamente artificial, de sucedâneo ${ }^{15}$. Em seguida afirma que "whiguismo" seria historicamente o nome correto para as idéias em que acredita: "Quanto mais aprendo a respeito da evolução das idéias, mais tenho consciência de que sou um impenitente Whig da velha guarda [Old Whig]"16 - com ênfase em Old.

É interessante notar que essa tentativa de Hayek de dizer que não é conservador ironicamente pode ser lida como profissão de fé num liberal-conservadorismo à moda britânica - tal como, aliás, o de dois pensadores que Hayek elenca entre suas principais influências: Edmund Burke (1729-1797), que criticou a arrogância racionalista da Revolução Francesa, em nome de uma noção dinâmica de tradição; e lorde Acton (1834-1902), que mesclou seu liberalismo com valores religiosos ${ }^{17}$.

Nos anos 1970, Friedrich von Hayek escreveu a ambiciosa trilogia Direito, Legislação e Liberdade (1973-1979). Dentre os vários temas discutidos nessa obra, vale destacar dois discutidos no volume III (A Ordem Política de um Povo Livre) que são decisivos para o posicionamento de Merquior sobre o pensamento hayekiano.

O primeiro deles é a discussão sobre o abuso do conceito de democracia; este termo estaria sendo privado de um significado claro, transformando-se "num fetiche verbal usado para envolver com um halo de legitimidade quaisquer exigências de um grupo desejoso de moldar algum aspecto da sociedade a seu bel prazer"18.

\footnotetext{
${ }^{15}$ Idem. Ibidem, p. 478.

${ }^{16}$ Idem. Ibidem, p. 479.

${ }^{17}$ MERQUIOR. O Liberalismo: Antigo e Moderno, p. 145.

${ }^{18}$ HAYEK, Friedrich August von. Direito, legislação e liberdade: uma nova formulação dos princípios liberais de justiça e economia política, v. 3: A ordem política de um povo livre. Trad. Maria Luiza X. de A. Borges. São Paulo: Visão, 1985, p. 42.
} 
Exemplo disso seria o fato de os regimes comunistas no Leste Europeu se autodenominarem "democracias populares". O autor deixa explícita sua insatisfação com tal corrupção da linguagem política ao admitir que, "se a democracia é entendida como governo conduzido pela vontade irrestrita da maioria, então não sou democrata e considero inclusive tal governo pernicioso e, a longo prazo, inexeqüível"19.

Hayek alega ser preciso adotar um novo termo para expressar o ideal original de democracia. A palavra grega kratos (que vem do verbo kratein) tem uma carga de violência, de força bruta, enquanto o verbo archein (do qual derivam, p.ex., monarquia e oligarquia) parece enfatizar melhor o governo segundo normas. Logo, demarquia é o termo que mais se aproxima do princípio da isonomia (lei aplicável igualmente para todos) ${ }^{20}$.

O segundo tema digno de destaque aparece em As Três Fontes dos Valores Humanos, o epílogo de Direito, Legislação e Liberdade: refiro-me à relação que Hayek traça entre evolução, tradição e progresso: "quando se evidencia que foi o desenvolvimento de uma tradição o que tornou possível a civilização, podemos pelo menos afirmar que a evolução espontânea é uma condição necessária, se não suficiente, do progresso" ${ }^{\prime 2}$. Hayek postula a tese da ordem espontânea, segundo a qual "as leis e instituições que tornam possível o processo social não foram criadas de forma deliberada, sendo antes de origem evolutiva e consuetudinária, e incorporando um enorme volume de experiências e informação prática acumulada ao longo de sucessivas gerações"22. A partir desta concepção, rejeita o racionalismo planejador ao ressaltar que são as boas tradições morais, e não o desígnio intelectual, "que possibilitaram o progresso no passado, assim como o possibilitarão no futuro" ${ }^{23}$.

\footnotetext{
${ }^{19}$ Idem. Ibidem, p. 43.

${ }^{20}$ Idem. Ibidem, p. 44.

${ }^{21}$ Idem. Ibidem, p. 180.

22 DE SOTO, Jesus Huerta. A Escola Austríaca. Trad. André Azevedo Alves. São Paulo: Instituto Ludwig von Mises Brasil, 2010, p. 126.

${ }^{23}$ HAYEK. Direito, legislação e liberdade, v. 3, p. 181.
}

Nesse sentido, Hayek critica o marxismo e a psicanálise (aliás, cabe notar, duas das principais bête noire de Merquior!) por instilarem princípios morais problemáticos, sendo eles respectivamente: o igualitarismo, que elimina o incentivo individual de observação das regras morais que havia na "estima diferenciada" perante os semelhantes, além de aumentar consideravelmente o poder de coerção da autoridade ao exigir que se tratem "diferentes pessoas de maneira diferenciada com o objetivo de colocá-las nas mesmas condições materiais" "24; e a liberação dos instintos naturais, selvagens, que estão levando à destruição dos valores culturais e civilizatórios ${ }^{25}$.

A partir desta exposição de alguns aspectos da obra hayekiana, é possível perceber que, se formos tomá-lo como expoente máximo do neoliberalismo, então esta doutrina postula algo bem moderado: a retomada do Rule of Law, isto é, do governo limitado. Segundo Hayek, as duas únicas funções do governo legítimo consistem "em prover uma estrutura para o mercado, e prover serviços que o mercado não pode fornecer" 26 .

Embora fosse um crítico ácido da "miragem da justiça social" que permeava o ideário de social-democratas (dentre eles os liberals americanos) e tenha alertado para as conseqüências moralmente deletérias de ideologias pseudo-progressistas (pelo menos segundo o conceito hayekiano de progresso) como o marxismo e a psicanálise, é importante ressaltar que Hayek "não se limitou a retroceder a um puro favorecimento do laissez-faire ou ao modelo de Estado vigia noturno"27.

Friedrich von Hayek, portanto, é um liberista, pois assim como Milton Friedman acreditava na tese da indivisibilidade da liberdade: "a menos que se obtenha ou se mantenha a liberdade econômica, as outras liberdades - civil

\footnotetext{
${ }^{24}$ Idem. Ibidem, p. 183.

${ }^{25}$ Idem. Ibidem, p. 186-187.

${ }^{26}$ MERQUIOR. O Liberalismo: Antigo e Moderno, p. 228.

${ }^{27}$ Idem. Ibidem, p. 229.
} 
e política - se desvanecem"28. Além disso, alega que a intervenção estatal na economia é negativa "porque faz com que a rede de informações do sistema de preços emita sinais enganadores, além de reduzir o escopo da experimentação econômica" 29. Mesmo assim, este autor está longe de fazer uma defesa irrestrita ou simplista da liberdade econômica e do Estado-mínimo: ele aceita a interferência governamental na previdência social, na educação ou mesmo subsidiando "certos desenvolvimentos experimentais"

Em um trecho bastante lúcido de seu ensaio sobre o pensador austríaco, Anthony de Crespigny defende-o da caricatura feita por muitos de seus críticos à esquerda (e também de alguns de seus pretensos epígonos):

Hayek foi descrito como um expoente do "laisser-faire", hostil à provisão pública de serviços sociais, indiferente às necessidades dos fracos, autoritário, antidemocrático, e assim por diante. No entanto, não se encontra na obra de Hayek nada que permita essas assertivas, o que torna difícil compreender como críticos presumivelmente escrupulosos chegaram a fazê-las ${ }^{31}$.

\section{III - A Posição de Merquior na Tradição Liberal}

Ao longo de sua trajetória intelectual, José Guilherme Merquior gradualmente mudou sua visão de mundo. Em seus primeiros escritos, simpatizava com o estruturalismo ${ }^{32}$

\footnotetext{
${ }^{28}$ Idem. Ibidem, p. 229.

${ }^{29}$ Idem. Ibidem, p. 228.

30 Vide: DOHERTY, Brian. Radicals for capitalism: a freewheeling history of the modern American libertarian movement. New York: Public Affairs, 2007, p. 551-552.
}

${ }^{31}$ CRESPIGNY, Anthony de. F. A. Hayek: Liberdade para o Progresso. In: Filosofia Política Contemporânea. Trad. Yvonne Jean. Brasília: Editora da Universidade de Brasília, 1979, p. 75.

32 Segundo o próprio Merquior, esta escola de pensamento social parte do conceito de estrutura como francês - principalmente com Lévi-Strauss (1908-2009) - e com a crítica cultural da Escola de Frankfurt; o exemplo máximo dessa primeira fase de sua obra é o ensaio Saudades do Carnaval - Introdução à crise da cultura (1972).

A partir da segunda metade da década de 1970, entretanto, Merquior se afastou dessas influências: passou a considerar que tanto estruturalistas e pós-estruturalistas ${ }^{33}$ quanto o marxismo ocidental ${ }^{34}$ partiam de dois pressupostos equivocados: "sua Kulturkritik pessimista, não baseada em nenhuma análise concreta, e sua rejeição sumária da modernidade e da ciência" ${ }^{35}$. Anos depois, escreveu que o marxismo ocidental - e, em De Praga a Paris, esta crítica também se aplica ao pós-estruturalismo - "foi apenas um episódio na longa história de uma velha patologia do

"um conjunto de relações abstratas definidas de modo formal e subentende um modelo válido para vários conteúdos diferentes, sendo estes ditos isomórficos exatamente porque compartilham a mesma estrutura." Vide: MERQUIOR, José Guilherme. De Praga a Paris. Trad. Ana Maria de Castro Gibson. Rio de Janeiro: Nova Fronteira, 1991, p. 19.

33 O pós-estruturalismo, que abrange autores como Michel Foucault (1926-1984) e Jacques Derrida (19302004), critica o paradigma estruturalista a partir de uma perspectiva formalista (que consiste na adoção de "análises imanentes" em vez de abordagens mais contextuais) e de uma apropriação niilista e decadentista do pensamento de Friedrich Nietzsche (1844-1900).

34 Vertente do pensamento marxista caracterizada pela epistemologia "humanística" (i.e., abordagem hermenêutica e crítica do naturalismo "cientificista"), pelo forte investimento na crítica cultural (tanto da arte erudita quanto da cultura de massa) e pelo ecletismo conceitual (envolvendo desde a psicanálise até a filosofia hegeliana). Dentre seus principais representantes podem ser citados György Lukács (1885-1971), Antonio Gramsci (1891-1937), Herbert Marcuse (1898-1979) e Theodor Adorno (1903-1969). Vide: MERQUIOR, José Guilherme. O Marxismo Ocidental. Trad. Raul de Sá Barbosa. Rio de Janeiro: Nova Fronteira, 1987, p. 19.

35 ROUANET, Sérgio Paulo. Merquior: obra política, filosófica e literária. In: MERQUIOR. O Liberalismo: Antigo e Moderno, p. 363. 
pensamento ocidental cujo nome é, e continua a ser, irracionalismo" 36 .

Duas figuras foram importantes na transição ideológica de José Guilherme: Roberto Campos, de quem foi conselheiro na embaixada de Londres, e Ernest Gellner (1925-1995), seu orientador no doutorado em Sociologia pela London School of Economics and Political Science.

Em 1979, pouco após concluir sua tese de doutorado sobre Rousseau e Weber ${ }^{37}$, Merquior assumiu uma perspectiva liberal e "neo-iluminista", marcada por uma ótica mais positiva sobre a modernidade. Em outras palavras, acreditava que permanecia legítima a tarefa de "tornar o homem mais livere, (...) aumentar sua racionalidade", e "refinar sua sensibilidade artística, num mundo em que a beleza seja irmã da razão e inseparável da liberdade" Essa adesão, portanto, transcendeu a discussão político-econômica: para José Guilherme, o liberalismo, além de ser uma doutrina política, era também "uma cosmovisão, identificada com a crença no progresso" 39 .

Dois ensaios que oferecem de forma sintética a perspectiva de Merquior sobre a tradição liberal são O Argumento Liberal (1981) e O Liberalismo: Antigo e Moderno. Em ambos faz uma história descritiva das idéias liberais, mas ainda assim é possível notar juízos de valor, tomadas de posição de José Guilherme diante das correntes e autores estudados.

John Locke (1632-1704) e Montesquieu (1689-1755), de acordo com o autor, foram mais ancestrais do que propriamente fundadores do liberalismo. Ambos legaram o imperativo da limitação do poder: Locke, por meio da noção de legitimidade baseada no consen-

${ }^{36}$ MERQUIOR. O Marxismo Ocidental, p. 277.

${ }^{37}$ Vide: Idem. Rousseau e Weber: Dois Estudos sobre a Teoria da Legitimidade. Trad. Margarida Salomão. Rio de Janeiro: Editora Guanabara, 1990.

${ }^{38}$ ROUANET. In: MERQUIOR. O Liberalismo: Antigo e Moderno, p. 370.

${ }^{39}$ MERQUIOR. O Liberalismo: Antigo e Moderno, p. 87. timento individual; Montesquieu, com sua análise da mecânica dos poderes ${ }^{40}$.

O liberalismo clássico (1780 a 1860) inclui pensadores como Benjamin Constant (17671830), Alexis de Tocqueville (1805-1859) e John Stuart Mill (1806-1873); a ênfase principal dessa fase da ideologia liberal foi a proteção da liberdade civil, i.e., o "livre exercício privado de agires e fazeres conforme a inclinação de cada um" ${ }^{\prime \prime}$.

Segundo Merquior, um dos problemas da primeira geração do liberalismo foi confundir a tendência de superação do militarismo pelo industrialismo com "um ilusório perecimento do estado" ${ }^{42}$. Tocqueville, aliás, foi um dos poucos liberais dessa geração que percebeu que "o crescimento da liberdade civil foi acompanhado, e na realidade pressupôs, uma tremenda expansão da regulamentação da sociedade (...) pelo estado enquanto foco emissor de direito"43.

Ao longo do século XIX, diante dos excessos da Revolução Francesa e dos levantes políticos de 1848, consolidou-se a segunda geração do pensamento liberal: o liberalismo conservador, formado por um tripé doutrinário composto por tradicionalismo (crença na sabedoria das instituições que resistiram ao teste do tempo), organicismo (visão comunitarista e holística da sociedade) e ceticismo político (desconfiança das teorias - especialmente aquelas com amplos propósitos inovadores quando aplicadas à vida pública ${ }^{44}$. Embora a crítica dos liberais-conservadores ao excessivo otimismo da filosofia da história progressista do liberalismo clássico seja pertinente, para Merquior o mesmo não se pode dizer de sua desconfiança diante da democracia: autores como Herbert Spencer (1820-1903), lorde Acton e até mesmo o argentino Juan Bautista

40 Idem. O Argumento Liberal. In: Revista Tempo Brasileiro, n⿳⺈ 65/66, abril-setembro. Rio de Janeiro: Tempo Brasileiro, 1981, p. 18-19.

${ }^{41}$ Idem. Ibidem, p. 19.

${ }^{42}$ Idem. Ibidem, p. 19.

${ }^{43}$ Idem. Ibidem, p. 19

${ }^{44}$ Idem. O Liberalismo: Antigo e Moderno, p. 141. 
Alberdi (1810-1884) receavam a massificação da política e procuraram retardar a democratização do liberalismo, defendendo a "ampliação cautelosa da inclusão do povo nos direitos políticos"45.

Nas últimas décadas do século XIX despontou o liberalismo social, corrente de autores de viés anti-utilitarista para quem a liberdade deveria ser vista como "algo a ser desfrutado por todos os membros da sociedade" ${ }^{46}$. Dentre os social-liberais podem ser elencados Thomas Hill Green (1836-1882) e Leonard Hobhouse (1864-1929), que buscaram restaurar a idéia de bem comum, rejeitaram os dogmas antiestatistas dos liberalismos clássico e conservador, mas não abandonaram a ótica individualista. Pelo contrário, o liberalismo social muito valoriza a individualidade, isto é, a "realização pessoal alcançada por meio da percepção da identidade ou das qualidades únicas de um indivíduo", a partir de uma concepção da liberdade "como uma força construtiva e positiva que confere aos indivíduos a capacidade (...) de adquirir autonomia ou alcançar a realização pessoal" 4 . A propósito, essa preocupação com a perfectibilidade do homem já havia aparecido em Constant e Stuart Mill; nesse aspecto foram muito influenciados pela ética humanista de Wilhelm von Humboldt (1767-1835) e seu "ideal de uma Bildung [formação, auto-cultivo] ao mesmo tempo moralizante e emancipatória"48.

Humboldt, representante máximo do liberalismo alemão ao lado de Immanuel Kant (1724-1804), define a liberdade como a possibilidade de uma atividade variada e indefini$\mathrm{da}$, sendo indispensável para que o indivíduo desenvolva de forma plena as suas capacidades. Este auto-aperfeiçoamento consiste em permitir que o ser humano "desfrute da mais absoluta liberdade para desenvolver a si mesmo a partir de suas próprias energias, em sua perfeita individualidade", sendo que "este vigor indivi-

\footnotetext{
${ }^{45}$ Idem, Ibidem, p. 183.

${ }^{46}$ Idem. O Argumento Liberal, p. 20.

${ }^{47}$ HEYWOOD. Ideologias Políticas, v. 1, p. 65.

${ }^{48}$ MERQUIOR. O Argumento Liberal, p. 20.
}

dual combina-se com a pluralística diversidade em prol da originalidade" 49 . Para entender melhor essa associação entre liberalismo e humanismo traçada por Merquior ${ }^{50}$, este trecho do ensaio de Humboldt sobre a Teoria da formação do ser humano é elucidativo:

A tarefa última de nossa existência, qual seja: conferir, pelos indícios de uma ação vital efetiva, um conteúdo tão grande possível ao conceito de humanidade presente em nossa pessoa, tanto durante o tempo de nossa vida quanto para além dela mesma ora, essa tarefa só se cumpre ao vincular-se o nosso eu ao mundo, a fim de se criar a interação mais geral, mais intensa e mais livre

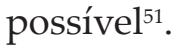

É compreensível, então, que em O Liberalismo: Antigo e Moderno Merquior destaque freqüentemente o legado deste pensador liberal alemão para uma concepção mais positiva da liberdade (isto é, que valorize a autonomia, o desdobramento do potencial humano), constituindo assim influência decisiva para o ideário social-liberal:

Humboldt exprimiu um tema liberal profundamente significativo: a preocupação humanista de formação da personalidade e aperfeiçoamento pessoal. Educar para a liberdade, e libertar para educar - esta era idéia da Bildung, a contribuição goethiana de Humboldt à filosofia moral. (...) Os novos liberais queriam implementar o potencial para o desenvolvimento do indivíduo que fora caro a Mill em seguimento a Humboldt,

49 HUMBOLDT, Wilhelm von. Os Limites da Ação do Estado. Trad. Jesualdo Correia. Rio de Janeiro: Topbooks, 2004, p. 145-151.

${ }^{50}$ Esta simpatia de José Guilherme Merquior à idéia humanista de "aprimoramento pessoal" aparece também em Algumas Reflexões sobre os Liberalismos Contemporâneos (1986); nela, enfatiza a conexão entre liberalismo e humanismo, a qual é "permeada pelo tema da excelência, da autoformação". Vide: MERQUIOR, José Guilherme. Algumas Reflexões sobre os Liberalismos Contemporâneos, p. 15-16.

${ }^{51}$ HUMBOLDT, Wilhelm von. Teoria da formação do ser humano. Trad. Paulo Astor Soethe. Linguagem, Literatura e Bildung. Werner Heidermann, Markus J. Weiniger (orgs.). Florianópolis, UFSC, 2006, p. 217. 
e ao fazê-lo pensaram no direito e no Estado como instituições habilitadoras. Esta preocupação com a liberdade positiva levou-os a ultrapassar o Estado minimalista ${ }^{52}$.

Segundo José Guilherme, esta fase social-liberal pode ser colocada entre Stuart Mill e John Maynard Keynes (1883-1946), sendo que "este foi seu grande economista, o diagnosticador e terapeuta das insuficiências do laissez-faire" ${ }^{\prime 53}$. Merquior assevera que as idéias de Keynes foram fundamentais para a renovação do capitalismo após a Grande Depressão, e concorda com a afirmação deste de que o desafio político da humanidade consiste em combinar três coisas: eficiência econômica, justiça social e liberdade individual ${ }^{54}$.

A partir da década de 1940, entretanto, começou uma gradual reação a essa vertente socializante do liberalismo e seu resultado prático, o Welfare State. Ludwig von Mises (1881-1973) e Hayek, principais economistas da Escola Austríaca, contribuíram para o ressurgimento do liberismo, isto é, da ênfase na liberdade econômica. Nos anos 70, este ideário - que ganhou legitimidade acadêmica depois que Hayek (em 1974) e Milton Friedman (em 1976) ganharam o Nobel de Economia - se configuraria politicamente no neoliberalismo: a partir da "convicção de que o progresso deriva automaticamente de uma soma não-planejada de iniciativas individuais", propôs-se "um desmantelamento do social-liberalismo, um retorno em regra ao Estado mínimo"55. Eis, portanto, a quarta grande fase do pensamento liberal, que Merquior chama de neoliberismo (que será tomado aqui como sinônimo de neoliberalismo).

Em O Argumento Liberal, José Guilherme considera o neoliberalismo essencialmente

\footnotetext{
${ }^{52}$ MERQUIOR. O Liberalismo: Antigo e Moderno, p. $56 ; 200$.

${ }^{53}$ Idem. O Argumento Liberal, p. 20.

54 Vide: KEYNES, John Maynard. Liberalism and Labour. In: Essays in Persuasion. London: Macmillan and Co., 1931, p. 307-312.

${ }^{55}$ MERQUIOR. O Argumento Liberal, p. 22.
}

uma reprise do liberalismo clássico, pois herda as deficiências deste último em matéria de visão histórica e consciência social. Além disso, acusa a doutrina neoliberal de ser uma "utopia liberal-conservadora", deficiente em matéria de visão histórica e consciência social e incapaz de atender "aos impulsos democratizantes das sociedades industriais de modelo liberal", muito menos às "exigências sociais dos países, como Brasil, onde a 'síntese democrático-liberal' permanece incompleta"56. Sendo assim, lhe "parece inevitável preferir, ao retrocesso neoliberal, uma retomada criadora do social-liberalismo" 57.

A propósito, esta "síntese democrático-liberal" é justamente o que José Guilherme encontra no pensamento político do sociólogo Raymond Aron (1905-1983) e do jurista Norberto Bobbio (1909-2004). Ambos permitem ao autor contrapor ao "hedonismo utilitário" dos neoliberistas um liberalismo democrático, apto a responder à altura os desafios políticos colocados pelas transformações sociais das últimas décadas.

Merquior, assim como Aron, não via a democracia representativa como entrave para a liberalização econômica, e concorda com a defesa que este sociólogo francês faz de "um amálgama de direitos civis e políticos tradicionais com modernos direitos sociais, que ele representa como direitos-créditos (droits-créances)" ${ }^{58}$. No que diz respeito a Bobbio, é enaltecida a preocupação deste jurista italiano em reafirmar a ligação entre o liberalismo e a democracia, criticando a negligência neoliberal diante das reivindicações igualitárias ${ }^{59}$. É a partir de abordagens como estas que o autor de O Liberalismo: Antigo e Moderno vislumbra uma potencial quinta fase do pensamento liberal, que seria uma versão atualizada do social-liberalismo.

Diante das diversas vertentes do liberalismo (clássico, conservador, social, neolibe-

\footnotetext{
${ }^{56}$ Idem. Ibidem, p. 22.

${ }^{57}$ MERQUIOR. O Argumento Liberal, p. 22.

${ }^{58}$ Idem. O Liberalismo: Antigo e Moderno, p. 238.

${ }^{59}$ Idem. Ibidem, p. 257-259.
} 
rista e, possivelmente, "neo-social"), percebemos em Merquior, por um lado, uma reserva em relação aos liberais-conservadores e aos neoliberais, pois discorda do temor de ambas correntes diante da democracia e de intervenções estatais que visem a diminuir a desigualdade social; por outro, é notável sua predileção pelo liberalismo social, alegando seu viés humanista e democrático. José Guilherme acreditava que "a liberdade política será sempre precária sem o aperfeiçoamento da igualdade"60. Em entrevista para o jornal Última Hora em 1982, este autor explica sua adesão a tal vertente liberal:

O liberalismo moderno é um social-liberalismo, é um liberalismo que não tem mais aquela ingenuidade, aquela inocência diante da complexidade do fenômeno social, e em particular do chamado problema social, que o liberalismo clássico tinha. $\mathrm{O}$ liberalismo moderno não possui complexos frente à questão social, que ele assume. É a essa visão do liberalismo que eu me filio ${ }^{61}$.

\section{IV - Merquior vs. HayeK: Em prol DA ORDEM ESPONTÂNEA, CONTRA O Ceticismo político, o Tradicio- NALISMO E O "NeO-EVOLUCIONIS- $\mathrm{MO}^{\prime \prime}$}

Na seção anterior, argumentei que Merquior não é um liberista, mas sim um social-liberal. Cabe agora verificar os seus posicionamentos sobre Hayek ao longo de sua produção ensaística na década de 1980, de forma a compreender suas afinidades e discordâncias em relação ao autor de Os Fundamentos da Liberdade.

Em O Argumento Liberal (1981), ao expor os pontos principais da doutrina neoliberal (ou neoliberista), José Guilherme considera F.

${ }^{60}$ ROUANET. In: MERQUIOR. O Liberalismo: Antigo e Moderno, p. 364.

${ }^{61}$ Vide: PEREIRA, José Mário. O fenômeno Merquior. In: MERQUIOR, José Guilherme. Verso Universo em Drummond, p. 339-340.
A. Hayek o seu maior profeta: este propunha "quietismo governamental, e simples legalismo no plano político-social", argumentando que a lei "se caracteriza pela sua neutra generalidade, equivalente à ausência de coerção social no sentido de uma opressão de classe ${ }^{62}$. Logo em seguida, contudo, Merquior busca refutar a nomocracia hayekiana (isto é, seu apego abstrato à Rule of Law) a partir de Raymond Aron: "a generalidade da lei não elimina seu aspecto eventualmente impositivo"; para certos grupos sociais, em certas circunstâncias, "a norma legal pode ser um poder ilegítimo"63.

Já no primeiro capítulo de A Natureza do Processo (1982), José Guilherme demonstra afinidade com a teoria da ordem espontânea de Hayek: concorda com o argumento do austríaco em favor da liberdade enquanto "ausência de controles sociais supérfluos e - do ponto de vista do bem comum - contraproducentes", assim como com sua crítica à "vá mas nefasta tentativa de submeter todo o processo social a uma prévia determinação, inspirada em nobres ideais"64.

Além disso, adere à noção hayekiana segundo a qual progresso é uma contínua adaptação, envolvendo conhecimento acumulado, prático e implícito, adquirido por e na experiência. Por fim, admite que "o progresso é um crescimento cumulativo que jamais poderia ter sido totalmente planejado", e que Hayek está certo ao denunciar na impressão contrária "os vícios do racionalismo e do intelectualismo" 65 .

No capítulo seguinte, contudo, há um trecho em que José Guilherme se afasta da filosofia da história individualista e antiestatista presente em muitos dos liberais do século XIX, mas também os novos liberistas: "Durkheim [1858-1917] mostrou que essa visão spenceriana da história como apoteose do individualismo (visão hoje reeditada por Hayek) era so-

\footnotetext{
${ }^{62}$ MERQUIOR. O Argumento Liberal, p. 22.

${ }^{63}$ Idem. Ibidem, p. 22.

${ }^{64}$ Idem. A Natureza do Processo, p. 35.

${ }^{65}$ Idem. Ibidem, p. 35.
} 
ciologicamente muito ingênua"66. Mais adiante em A Natureza do Processo, o autor aponta um problema comum aos neoliberais e a certa esquerda "estadofóbica", isto é, que demoniza o Estado e mitifica e superestima a sociedade civil - mas, ainda assim, poupa Hayek de ser reduzido ao que chama de "neoliberalismo vulgar" 67 :

Hoje em dia, o neoliberalismo - em muita coisa, um renascimento anacrônico do liberalismo clássico - quer ressuscitar essa errônea contraposição do estado à sociedade. Nos neoliberalismos sofisticados, como o de Hayek, a estadofobia se cinge ao plano econômico, mas reconhece o valor do estado como ordenamento jurídico. Já no neoliberalismo vulgar, o anátema recai sobe toda e qualquer forma de presença do estado ${ }^{68}$.

Em 1986, durante sua palestra no Instituto Liberal intitulada Algumas Reflexões sobre os Liberalismos Contemporâneos, Merquior faz um longo comentário sobre Friedrich von Hayek. Primeiro alude à controvérsia Croce-Einaudi e elogia o austríaco por sua

${ }^{66}$ Idem. Ibidem, p. 44.

${ }^{67}$ José Guilherme Merquior volta a criticar a banalização da doutrina neoliberal em Algumas Reflexões sobre os Liberalismos Contemporâneos: "não devemos confundir, enquanto liberais lúcidos e modernos, a nossa legítima alergia à expansão imoderada do Estado nos terrenos em que ele não deveria e não precisa expandir-se imoderadamente com uma posição barata, ingênua, historicamente ignara, sociologicamente inepta, que consistiria numa espécie de rejeição indiscriminada da idéia do Estado, das instituições do Estado (...). Pertence, afinal de contas, às próprias entranhas da posição e da doutrina liberais a preocupação com uma ordem jurídica. (...) Penso eu em Locke, em Montesquieu, (...) ou, em nosso tempo, no próprio Hayek, cuja Constitution of Liberty possui páginas mostrando a importância de categorias como DIREITO, ORDEM e vale dizer, ESTADO. (...) Acho lamentável que alguns grupos, dizendo valer-se de Hayek, adotando o que eu chamaria de hayekismo vulgar, invistam contra o Estado em todos os planos e de todas as maneiras." Vide: Idem. Algumas Reflexões sobre os Liberalismos Contemporâneos, p. 18; grifo meu.

${ }^{68}$ Idem. A Natureza do Processo, p. 140. contribuição para o reconhecimento da necessidade da liberdade econômica, coroada com o Nobel de Economia e o "renascimento liberal" no último quartel do século XX: "Se, hoje em dia, acreditamos que Einaudi tinha razão e que Croce estava errado quanto ao liberismo, (...) no plano do pensamento, quem mais nos ajudou a ver isso foi Hayek"69.

José Guilherme Merquior, entretanto, demonstra um afastamento ideológico e epistemológico em relação à obra hayekiana dos anos 1970 e 80; não aprecia a combinação que há nela de um conservadorismo à la Burke, segundo o qual "a própria persistência das instituições no tempo contém em si um elemento de sábia superioridade", com uma teodicéia parecida com a de Gottfried Wilhelm Leibniz (1646-1716), marcada por uma "visão sempre otimista de uma harmonia universal, misteriosamente conseguida por vias não intencionais"70. Além disso, compartilha a preocupação de John Gray (1948) ${ }^{71}$ e Karl Popper (1902-1994) quanto a uma tardia guinada neo-evolucionista de Hayek:

Hayek estaria escrevendo, cada vez mais, como um Spencer redivivo. Ou seja, um homem que abraça, sempre mais, uma perspectiva evolucionista, a ponto mesmo de diluir, dissolver a perspectiva ética, o plano do juízo ético, da avaliação ética, numa visão evolucionista (...) insustentável. Menciono isso como última pílula daquilo que é, hoje, problemático no desenvolvimento da obra de Hayek: o fato de que ele está soando, em tom sempre mais intenso, como um Spencer sofisticado, numa clara volta às posições básicas

${ }^{69}$ Idem. Algumas Reflexões sobre os Liberalismos Contemporâneos, p. 11.

${ }^{70}$ Idem. Ibidem, p. 12-13.

${ }^{71}$ John Gray alega que o pensamento de Hayek carece de uma visão mais consistente sobre justiça e direitos morais;issoolevanãosóauma problemática combinação teórica de individualismo e tradicionalismo, mas também a se ancorar num ceticismo epistemológico que poderia se voltar justamente contra a ordem social liberal que ele defende. Vide: GRAY, John. F. A. Hayek on Liberty and Tradition. In: The Journal of Libertarian Studies, Vol. IV, No. 2 (Spring 1980), p. 133-134. 
do evolucionismo de final do século pas$\operatorname{sado}^{72}$.

A postura crítica de Merquior sobre o pensamento hayekiano permanece em seu último livro, O Liberalismo: Antigo e Moderno (escrito em 1989, mas publicado em 91). Primeiro discorda de seu "repúdio quixotesco à democracia majoritária (substituída por uma visão condicionada, 'demarquia')", insinuando que este excessivo ceticismo político o coloca na companhia de liberais-conservadores ${ }^{73}$. Embora Hayek não se considere um conservador (como vimos no capítulo II deste ensaio), Merquior aponta a ironia que há na guinada tradicionalista de seu pensamento sociopolítico a partir dos anos 1970: seu entusiasmo cada vez menor pela democracia poderia ser interpretado como uma refutação da tese de O Caminho da Servidão, ensaio de 1944 no qual o austríaco alertara para o risco de o planejamento econômico ser uma ameaça ao regime democrático. José Guilherme observa que, se a democracia desimpedida "milita contra o mercado, pelo menos ela obviamente sobreviveu, em vez de perecer durante o prolongado crescimento do Estado social"74.

Merquior, assim como John Gray ${ }^{75}$, também aponta o abismo que há na obra tardia de F. A. Hayek entre a "valorização liberal clássica de governo limitado, mercados livres e o governo da lei" e a "mística burkiana, que afirma muitas vezes, mais do que prova, a sabedoria oculta das instituições há muito existentes"76. Eis que se revela outra ironia: a partir desse evolucionismo burkiano se poderia alegar uma sabedoria inerente não só ao progresso e ao mercado, mas também "às instituições há muito existentes que Hayek tanto detesta, como controle de renda, controle de preços e taxação

72 MERQUIOR. Algumas Reflexões sobre os Liberalismos Contemporâneos, p. 14.

\footnotetext{
${ }^{73}$ Idem. O Liberalismo: Antigo e Moderno, p. 230-231.

${ }^{74}$ Idem. Ibidem, p. 227.

${ }^{75}$ Vide nota 71.

${ }^{76}$ Idem. Ibidem, p. 231.
}

progressiva"77. José Guilherme argumenta que a maioria dos Estados de bem-estar social "não se fundaram com base em um planejamento abrangente e consciente", sendo na verdade o "resultado de muitas evoluções imprevistas"78.

As críticas contundentes de Merquior a Hayek chegam ao ápice quando aquele alega que o austríaco vê a liberdade apenas como instrumento de progresso: "o mérito supremo do indivíduo 'hayekiano' é contribuir (inconscientemente) para a evolução social", e tal tese o afastaria de um individualismo baseado na idéia de auto-aperfeiçoamento, tal como no liberalismo alemão (Humboldt) e no social-liberalismo britânico (Mill e Hobhouse); sendo assim, "o neoliberismo, assim como o neo-evolucionismo, terminar por minar o próprio âmago da ética liberal"79.

A propósito, José Guilherme se ampara aqui em um comentário feito por Anthony de Crespigny anos antes, em F. A. Hayek: Liberdade para o Progresso, sobre a defesa instrumental (e relativamente elitista) que Hayek fizera da liberdade no $2^{\mathrm{o}}$ capítulo de Os Fundamentos da Liberdade. De acordo com Crespigny, o austríaco restringe as vantagens da liberdade à possibilidade de alcançar progressos civilizatórios, mas também insinua "ser melhor a liberdade de alguns do que a de ninguém, e a liberdade total de muitos do que a liberdade limitada de todos" ${ }^{\prime 8}$. Segundo Crespigny (e Merquior endossa essa crítica),

...parece estranho que um individualista liberal defenda um tipo de liberdade que deixa de enfatizar devidamente a inconveniência de obstáculos deliberadamente impostos aos desejos ou atividades efetivas, ou possíveis, do indivíduo "qua" indivíduo. (...) Absolutamente não é evidente que em qualquer sociedade dada a liberdade de alguns seja necessariamente melhor do que a falta de liberdade para todos. Na realidade,

\footnotetext{
77 Idem. Ibidem, p. 231.

${ }^{78}$ Idem. Ibidem, p. 232.

${ }^{79}$ Idem. Ibidem, p. 232-233.

${ }^{80}$ CRESPIGNY. Filosofia Política Contemporânea. p. 82.
} 
uma sociedade onde alguns fossem livres e outros não, poderia ser muito pior do que uma sociedade onde todos fossem oprimidos, e seria pior justamente devido aos efeitos sobre o amor próprio das pessoas ${ }^{81}$.

Hayek, portanto, preocupou-se tanto em favorecer a liberdade econômica - enquanto espontaneidade do mercado - e em restringir a interferência da esfera pública sobre a privada que teria colocado a própria ética do liberalismo (no sentido de uma preocupação com o auto-aperfeiçoamento e o pluralismo) em risco.

\section{V - CONSIDERAÇÕES FINAIS}

Ao longo deste ensaio procurei argumentar, em primeiro lugar, que José Guilherme Merquior não pode ser considerado um neoliberal ou liberista stricto sensu: embora reconheça a importância da liberdade econômi$\mathrm{ca}$, as suas afinidades intelectuais e políticas estão com o liberalismo social. Merquior simpatiza com esta vertente da história do pensamento liberal porque ela, no plano teórico, é uma tentativa de conciliar liberdade e igualdade, valorizando mais a participação política do que o liberalismo clássico, o conservador e o neoliberal; a proposta social-liberal também é um esforço de aproximar o liberalismo do ideal da Bildung, isto é, de uma ética humanista, uma visão mais nobre da condição humana (mas, evitando uma filosofia da história demasiadamente otimista e "estadofóbica"). No plano prático, o social-liberalismo de Merquior consiste em uma adesão limitada ao livre mercado, pois julga que certas intervenções do Estado são importantes não só para promover a igualdade de oportunidades, mas também para estimular a liberdade positiva enquanto virtude cívica.

Em segundo lugar, no que diz respeito à comparação com a filosofia política liberista de Friedrich von Hayek, busquei demonstrar

\footnotetext{
${ }^{81}$ Idem. Ibidem, p. 82-83.
}

que, em várias dos ensaios de sua última década de vida (inclusive o derradeiro deles, $\mathrm{O}$ Liberalismo: Antigo e Moderno), Merquior manteve uma postura ambivalente, mas majoritariamente crítica em relação aos postulados hayekianos.

Ambos convergem em pelo menos três pontos: José Guilherme enaltece a reafirmação da liberdade econômica feita pelo austríaco; concorda com a teoria da ordem espontânea como explicação do progresso das sociedades modernas; compartilha do ceticismo de Hayek em relação ao racionalismo "construtivista" e ao planejamento governamental, na medida em que essa "arrogância fatal" costuma resultar em ineficiência econômica e em burocratização política.

Merquior, contudo, diverge das conclusões epistemológicas e políticas de F. A. Hayek. Epistemologicamente, porque não concorda com a infusão de tradicionalismo burkiano e neo-evolucionismo spenceriano que marcaria obras hayekianas tardias como Direito, Legislação e Liberdade, as quais emanariam uma "cega confiança de Hayek na ciência da evolução como tradição"82; no âmbito político, pois discorda da redução da democracia à demarquia (algo que lhe soa como uma utopia regressiva), assim como da concepção nomocrática de Estado segundo a qual bastaria definir as regras do jogo, sem se preocupar com reivindicações mais substantivas e igualitárias.

Voltando a Roberto Campos, em seu prefácio a $O$ Liberalismo: Antigo e Moderno este economista afirma, sem esconder sua discordância, que Merquior teria redigido considerações "generosas demais no tocante a Keynes, e generosas de menos no tocante a Hayek" "83. Faltam, no entanto, evidências mais concretas de que seu amigo de fato estava se tornando um liberista em seus últimos meses de vida. Estou mais inclinado a pensar que José Guilher-

${ }^{82}$ MERQUIOR. O Liberalismo: Antigo e Moderno, p. 232.

${ }^{83}$ CAMPOS. In: MERQUIOR. O Liberalismo: Antigo e Moderno, p. 28. 
me Merquior, mesmo quando se converteu ao credo liberal, manteve-se republicano, isto é, conservou sua valorização da participação política e sua crença na capacidade da vida democrática de elevar o caráter dos cidadãos. Nesse aspecto se aproxima um pouco do liberalismo anti-utilitarista de Benedetto Croce.
É importante relembrar, contudo, que Merquior reconhece a vitória póstuma de Einaudi através de Hayek, isto é, a relação indissociável entre a liberdade econômica e a política - ou, nos termos mais amplos de Isaiah Berlin, entre a liberdade negativa e a positiva. cos 